\title{
UTICAJ PROSTORNOG RASPOREDA ŠUMSKIH KAMIONSKIH PUTEVA NA SREDNJU TRANSPORTNU DISTANCU PRIVLAČENJA ${ }^{1}$ The impact of spatial allocation of forest roads on mean skidding distance
}

\author{
Dževada Sokolović \\ Šumarski fakultet Sarajevo
}

Sažetak

\begin{abstract}
Abstact
The building of forest road is economically justified only if it causes shorting of mean skidding distance. Due to this fact determination of mean skidding distance is very important in forests accessibility. This paper presents the short review of classic and modern methods (computer aided) for determination of mean skidding distance. Management unit "Plješevica" has been selected as the research area, where the mean skidding distance has been calculated for several options of forest roads network by central point method - computer aided.
\end{abstract}

Key words: forest roads, mean skidding distance, economicalyy jusified building costs, central point method.

\section{Uvod}

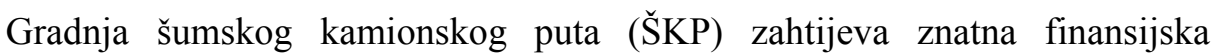
sredstva koja moraju imati svoje ekonomsko opravdanje. Isplativost gradnje šumskog kamionskog puta će se iskazati vremenom, prije svega uštedama u troškovima privlačenja drvne mase radi skraćivanja srednje transportne distance privlačenja (STDP). Gradnja ma kojeg šumskog kamionskog puta ima za posljedicu skraćivanje srednje transportne distance privlačenja. Međutim, konačni cilj kojem se teži kod gradnje šumskih kamionskih puteva, odnosno kod rješavanja otvaranja šumskog područja jeste optimalna mreža šumskih kamionskih puteva, jer optimum podrazumijeva minimum ukupnih troškova.

Srednja transportna distanca privlačenja predstavlja dužinu puta kojom se drvna masa rasuta po sječini privlači do jednog stovarišta. Računanje srednje transportne distance privlačenja za svaki tovar posebno oduzelo bi jako puno vremena.

\footnotetext{
${ }^{1}$ Rad prezentitiran na II Simpoziju poljoprivrede, veterinarstava, šumarstva i biotehnologije - Strategija razvoja domaće proizvodnje, 28 - 30 septembat/rujan 2004 Bihać
} 
Analizom se došlo do zaključka da je rad potreban za privlačenje drvne mase količine Q koja je raspršena po površini i mehanički rad potreban za privlačenje iste količine drvne mase Q koja se zamišljeno skoncentriše na jednom mjestu jednak tj. transportni momenti za ova dva slučaja su jednaki. Zbog toga se kod računanja srednje transportne distance privlačenja polazi od pretpostavke da je sva drvna masa skoncentrisana u težištu površine.

Srednja transportna distanca privlačenja može se izračunati:

a) klasičnim načinom (grafički, matematički metod, itd.),

b) uz pomoć odgovarajućih računarskih metoda i tehnologija.

Računare za određivanje srednje transportne distance privlačenja su, kako je poznato, koristili: Shiba i Löfler (1990), Knežević (1990), Dürsten (1992), Sessions (1992), Pičman (1993), Brajković (1997), Pentek (2002) itd.

Pičman (1993) ističe: "Budućnost projektiranja šumskih cesta, odnosno određivanja stvarne i optimalne otvorenosti nekoga šumskog predjela, prosječne odnosno srednje udaljenosti privlačenja leži upravo u primjeni osobnih računala uz odgovarajuće programe i tehnička pomagala."

Cilj ovoga rada jeste da analizom provedenom uz pomoć računara prikaže uticaj pravilnog prostornog rasporeda ŠKP na srednju transportnu distancu privlačenja.

\section{Metode rada}

Za analizu uticaja prostornog rasporeda ŠKP na srednju transportnu distancu privlačenja korišten je računar sa određenim programima.

Sve površine (odjeli, odsjeci,...) i dužine (putevi, srednje geometrijske transportne distance privlačenja) određene su pomoću GIS- softwera - WinGis 2003. Težište površine određeno je pomoću softwera Arc View.

Da bi se planirana analiza mogla provesti pomoću računara bilo je potrebno:

- georeferensirati topografsku kartu analiziranog područja,

- digitalizirati karte sa gospodarskom podjelom, gdje se vide granice odjela i odsjeka,

- kreirati baze podataka za ove prostorne jedinice,

- digitalizirati puteve na ovom području i to:

$>$ šumske kamionske puteve koji se nalaze unutar gospodarske jedinice,

$>$ javne puteve koji se nalaze u neposrednoj blizini GJ (na udaljenosti manjoj od $300 \mathrm{~m}$ te tako otvaraju ovu GJ).

- povezivanje sloja puteva sa bazom podataka. 

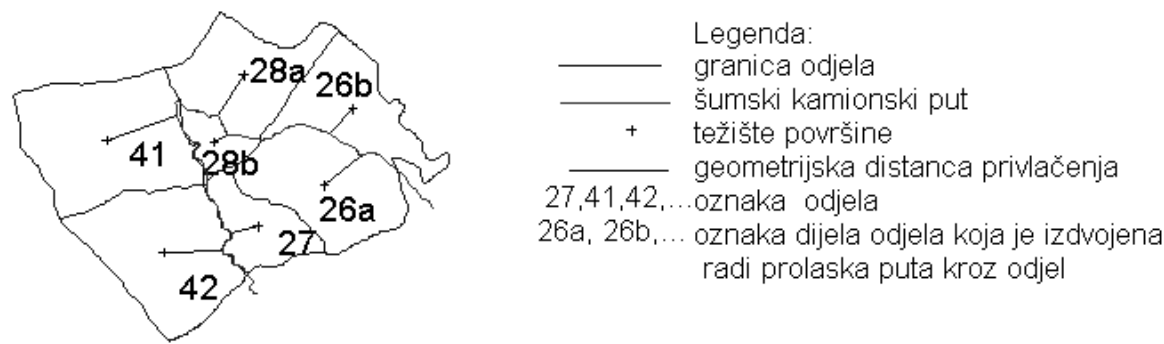

Slika 1. Šematski prikaz određivanja geometrijske srednje transportne distance privlačenja

Figure 1 The scheme of determining geometrical mean skidding distance

Napomena

U slučaju kad kamionski put dijeli odjel traži se težište dijela odjela koji odvaja put. Neto drvna masa za ove odvojene površine računa se prema procentualnom učešću datih površina u ukupnoj površini cijelog odjela, uz usvojenu pretpostavku da je drvna masa unutar odjela ravnomjerno raspoređena.

Geometrijska srednja transportna distanca privlačenja računat će se pomoću obrasca:

gdje je:

$$
l_{g}=\frac{\Sigma m \cdot l}{\Sigma m}
$$

lg - geometrijska srednja transportna distanca privlačenja, $\mathrm{m}$

$\Sigma \mathrm{m}$ - zapremina drvne mase za privlačenje, $\mathrm{m} 3$

1 - udaljenost težišta površine do najbližeg puta, $m$

Stvarna srednja transportna distanca privlačenja: $l_{s}=l_{g} \cdot r$ gdje je:

ls - stvarna srednja transportna distanca privlačenja u m

lg - geometrijska srednja transportna distanca privlačenja u m

r - ukupni koeficijent razvijanja (utvrđuje se na osnovu prosječnog nagiba terena i određuje povećanje dužine privlačenja zbog nagiba terena i krivudanja putanje privlačenja drveta).

\subsection{Područje istraživanja}

Analiza će se provesti na dijelu gospodarske jedinice „Plješevica“, koja se nalazi u okviru Unskog Šumsko Privrednog Područja. Analiza obuhvata odjele od 17 do 76 ukupne površine 5853,2 ha. U radu će se radi jednostavnosti pisanja odjeli GJ „Plješevica“, koji su predmet analize i koji zauzimaju 77,48 \% ukupne površine GJ, nazivati GJ "Plješevica". 
Nažalost, 28,43 \% od analizirane površine je miniranio. Pretpostavka u radu je da će ove površine u skorije vrijeme biti deminirane. Za analizu su uzeti potrebni podaci iz trenutno važeće ŠPO za ovo područje.

\section{Rezultati istraživanja}

Analiza je urađena za tri varijante mreže šumskih kamionskih puteva:

1. varijanta I - sadašnja mreža

2. varijanta II - teoretski model otvaranja GJ "Plješevica"

3. varijanta III - sadašnja poboljšana mreža

\subsection{Varijanta I - sadašnja mreža ŠKP}

$\mathrm{Na}$ slici 2 data je karta sa određenim težištima površina i ucrtanim geometrijskim srednjim transportnim distancama privlačenja za sadašnju mrežu puteva - varijanta 1 .

Podaci o površini odjela ili dijelova odjela, neto masi za transport, geometrijskoj udaljenosti težišta površine do najbližeg puta i moment privlačenja izračunati su za sve odjele u GJ, a kao primjer obračuna u tabeli 1 prikazani su podaci za odjele 17, 18 i 19.

Izmjerena postojeća ukupna dužina puteva (šumski kamionski putevi i javni putevi) u GJ "Plješevica" iznosi $77707 \mathrm{~m}$.

Na osnovu podataka iz slike 2 i tabele 1 izračunata je:

- geometrijska srednja transportna distanca privlačenja za sadašnju mrežu puteva:

$$
l_{g_{S}}=\frac{\Sigma m \cdot l}{\Sigma m}=\frac{135384124,6}{288526}=469,23 m
$$

- stvarna srednja transportna distanca privlačenja za sadašnju mrežu puteva:

$$
l_{s S}=l_{g S} \cdot r=469,23 \cdot 1,309=614,22 \mathrm{~m}
$$

(Za prosječan poprečni nagib terena $31,5 \%$, koliko je izmjereno na ovom području $r=$ 1,309.) 
Tabela 1. Geometrijska STDP za varijantu I

Table 1 Geometrical mean skidding distance for variant I

\begin{tabular}{|c|c|c|c|c|}
\hline $\begin{array}{c}\text { Broj odjela } \\
\text { Number of } \\
\text { compartment }\end{array}$ & $\begin{array}{c}\text { Površina } \\
\text { Area }\end{array}$ & $\begin{array}{c}\text { Neto etat } \\
(\mathrm{m}) \\
\text { Harvesting } \\
\text { volume } \\
(\mathrm{m})\end{array}$ & $\begin{array}{c}\text { Geometrijska } \\
\text { distanca } \\
\text { privlačenja } \\
\text { Geometrical } \\
\text { mean skidding } \\
\text { distance }(1)\end{array}$ & $\begin{array}{c}\text { Moment } \\
\text { privlačenja } \\
\Sigma m \cdot l\end{array}$ \\
\begin{tabular}{c|c|c|c|} 
Skidding moment \\
$\Sigma m \cdot l$
\end{tabular} \\
\hline $17 \mathrm{a}$ & 150,9 & 3168,54 & $\mathrm{~m}$ & $\mathrm{~m}^{4}$ \\
\hline $17 \mathrm{~b}$ & 80,39 & 1688,20 & 250,62 & 1365386,04 \\
\hline 18 & 168,1 & 6562,89 & 811,41 & 423164,92 \\
\hline 19 & 113,6 & 5197,52 & 445,55 & 2325194,58 \\
\hline
\end{tabular}

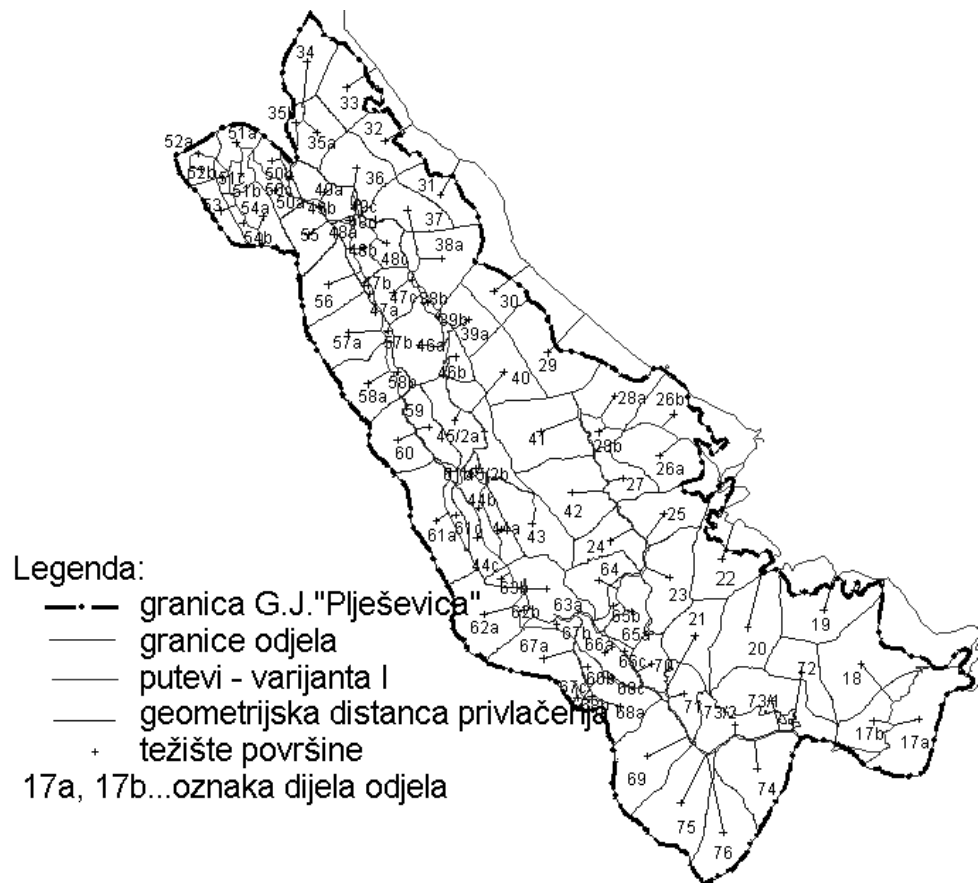

Slika 2. Određivanje geometrijske STDP za varijantu I

Figure 2 Determining geometrical mean skidding distance for variant I 


\subsection{Varijanta II - teoretski model otvaranja GJ "Plješevica"}

Teoretski model otvaranja GJ "Plješevica" je dat uz polaznu pretpostavku da se sa otvaranjem ove šumske površine polazi od nule. Dužina mreže šumskih kamionskih puteva približno je jednaka dužini mreže ŠKP za varijantu I - sadašnja mreža.

Prilikom polaganja idejnih trasa ŠKP za varijantu II vodilo se računa o prostornom rasporedu istih, odnosno težilo se da međusobni razmak između puteva bude približno jednak kada je to konfiguracija terena dozvoljavala.Teoretski model mreže ŠKP i određivanje geometrijske srednja transportne distance privlačenja dat je na slici 3, a kao primjer za provedenu analizu u tabeli u 2 prikazani su podaci za odjele 17 i 18.

Ukupna dužina idejnih trasa ŠKP za varijantu II je $80626 \mathrm{~m}$.

- geometrijska srednja transportna distanca privlačenja za varijantu II:

$$
l_{g_{S}}=\frac{\Sigma m \cdot l}{\Sigma m}=\frac{100207260}{288526}=347,3 m
$$

- stvarna srednja transportna distanca privlačenja za varijantu II:

$$
l_{s S}=l_{g S} \cdot r=347,3 \cdot 1,309=454,6 m
$$

Tabela 2. Geometrijska STDP za varijantu II

Table 2 Geometrical mean skidding distance for variant II

\begin{tabular}{|c|c|c|c|c|}
\hline $\begin{array}{c}\text { Broj odjela } \\
\text { Number of } \\
\text { compartment }\end{array}$ & $\begin{array}{c}\text { Površina } \\
\text { Area }\end{array}$ & $\begin{array}{c}\text { Neto etat } \\
(\mathrm{m}) \\
\text { Harvesting } \\
\text { volume } \\
(\mathrm{m})\end{array}$ & $\begin{array}{c}\text { Geometrijska } \\
\text { distanca } \\
\text { privlačenja }(\mathrm{l}) \\
\text { Geometrical } \\
\text { mean skidding } \\
\text { distance }(1)\end{array}$ & $\begin{array}{c}\text { Moment } \\
\text { privlačenja } \\
\mathrm{\Sigma m} \cdot l\end{array}$ \\
$\begin{array}{c}\text { Skidding moment } \\
\mathrm{\Sigma m} \cdot l\end{array}$ \\
\hline $17 \mathrm{a}$ & 73,38 & 1539,59 & 241,7 & $\mathrm{~m}^{4}$ \\
\hline $17 \mathrm{~b}$ & 157,9 & 3317,15 & 390,4 & 1295016,7 \\
\hline $18 \mathrm{a}$ & 10,33 & 403,37 & 16,7 & 6736,3 \\
\hline $18 \mathrm{~b}$ & 157,7 & 6162,55 & 586,3 & 3613105,2 \\
\hline
\end{tabular}




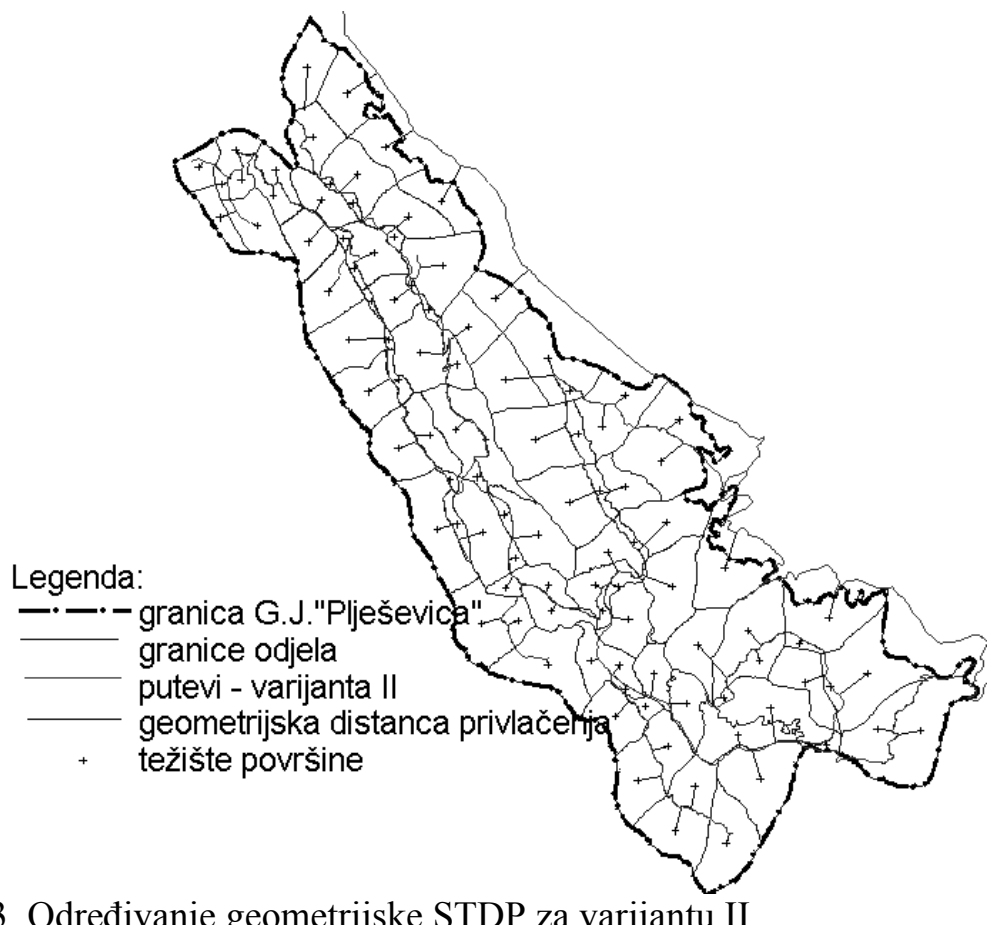

Slika 3. Određivanje geometrijske STDP za varijantu II

Figure 3 Determining geometrical mean skidding distance for variant II

Prema istraživanjima velikog broja svjetskih autora, optimalna srednja transportna distanca je unutar intervala 300 do $500 \mathrm{~m}$, ovisno od toga da li su tereni nešto povoljniji ili se radi o teškim planinskim terenima.

Dobijena stvarna STDP za varijantu II ulazi u dati interval koji se smatra optimalnim.

Varijanta II predstavlja teoretski model za otvaranje GJ "Plješevica," koji nije realan jer polazi od pretpostavke da se sa otvaranjem ovog područja polazi od nule. Međutim, u GJ „Plješevica“ već je izgrađena mreža ŠKP u dužini od 77707 m, pa se sa otvaranjem ove šumske površine ne može početi od nule. S obzirom da su varijantom II postignuti značajni rezultati skraćivanja srednje transportne distance privlačenja, tražila se mogućnost za konkretnu primjenu datog teoretskog modela na postojećoj mreži ŠKP. Uočene su idejne trase ŠKP kojima se značajno skraćuje srednja transportna distanca privlačenja određenih dijelova površine pomenute GJ. Ove idejne trase su se uklopile u postojeću mrežu ŠKP i tako je nastala varijanta III. 


\subsection{Varijanta III - sadašnja poboljšana mreža ŠKP}

U varijanti III su date idejne trase ŠKP kojima se utiče na značajno skraćivanje srednje transportne distance privlačenja. Varijanta III - sadašnja poboljšana mreža data je na slici 4, a primjer provedene analize dat je u tabeli 3 za odjele 17 i 18 .

Tabela 3. Geometrijska STDP za varijantu III

Table 3 Geometrical mean skidding distance for variant III

\begin{tabular}{|c|c|c|c|c|}
\hline $\begin{array}{c}\text { Broj odjela } \\
\text { Number of } \\
\text { compartment }\end{array}$ & $\begin{array}{c}\text { Površina } \\
\text { Area }\end{array}$ & $\begin{array}{c}\text { Neto etat } \\
(\mathrm{m}) \\
\text { Harvesting } \\
\text { volume } \\
(\mathrm{m})\end{array}$ & $\begin{array}{c}\text { Geometrijska } \\
\text { distanca } \\
\text { privlačenja } \\
\text { Geometrical } \\
\text { mean skidding } \\
\text { distance }(1)\end{array}$ & $\begin{array}{c}\text { Moment } \\
\text { privlačenja } \\
\Sigma m \cdot l\end{array}$ \\
\begin{tabular}{c|c|c|c|} 
Skidding moment \\
$\Sigma m \cdot l$
\end{tabular} \\
\hline $17 \mathrm{a}$ & 150,9 & 3168,54 & $\mathrm{~m}$ & $\mathrm{~m}^{3}$ \\
\hline $17 \mathrm{~b}$ & 80,39 & 1688,20 & 250,63 & 1365386 \\
\hline $18 \mathrm{a}$ & 10,13 & 395,74 & 16,94 & 423164,9 \\
\hline $18 \mathrm{~b}$ & 157,9 & 6167,15 & 585,55 & 36703,87 \\
\hline
\end{tabular}

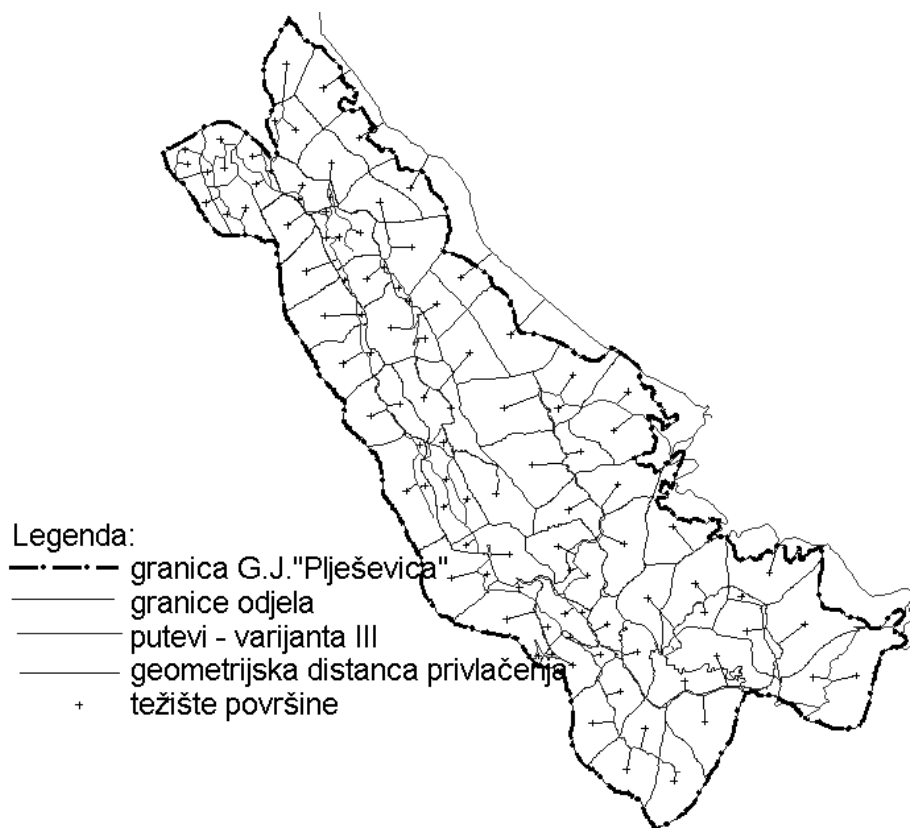

Slika 4. Određivanje geometrijske STDP za varijantu III

Figure 4 Determining geometrical mean skidding distance for variant III 
Ukupna dužina mreže ŠKP za varijantu III je 87186 m.

- geometrijska srednja transportna distanca privlačenja za varijantu III:

$$
l_{g_{S}}=\frac{\Sigma m \cdot l}{\Sigma m}=\frac{104345781,8}{288526}=361,7 m
$$

- stvarna srednja transportna distanca privlačenja za varijantu III:

$$
l_{s S}=l_{g S} \cdot r=361,7 \cdot 1,309=473,5 m
$$

\section{Diskusija i zaključci}

Cilj rada bio je da pokaže način računanja srednje transportne distance privlačenja pomoću računara težišnim metodom, i uticaj prostornog rasporeda šumskih kamionskih puteva na dužinu srednje transportne distance privlačenja.

Određivanje srednje transportne distance privlačenja težišnim metodom pomoću računara predstavlja veoma brz i tačan metod. Pomoću računara moguće je dati više varijanti mreža šumskih kamionskih puteva i potom analizom izabrati varijantu kojom je srednja transportna distanca privlačenja najmanja.

$\mathrm{Na}$ osnovu provedene analize može se zaključiti da varijante I i II imaju približno jednaku dužinu mreže šumskih kamionskih puteva, oko $80000 \mathrm{~m}$. Međutim, radi boljeg prostornog rasporeda puteva, stvarna srednja transportna distanca privlačenja za varijantu II manja je za oko $160 \mathrm{~m}$ od stvarne srednje transportne distance privlačenja kod varijante I.

Varijanta III je data kao realno moguća mreža šumskih kamionskih puteva sa ciljem smanjivanja srednje transportne distance privlačenja. Dobijena stvarna srednja transportna distanca privlačenja za varijantu III iznosi 473,5 m i manja je od sadašnje za oko $141 \mathrm{~m}$.

Smanjivanje srednje transportne distance privlačenja jedan je od najvažnijih zadataka gradnje šumskih kamionskih puteva, jer se na taj način postižu velike uštede u troškovima privlačenja. Zbog toga precizno i brzo određivanje srednje transportne distance privlačenja umnogome olakšava konačni izbor položaja šumskih kamionskih puteva. 


\section{Literatura}

1. Abegg, B., 1978: Die Shätzung der optimalen Dichte von Waldstraßen in traktorfahrbaren Gelande. Eidg. Antalt für das forstiche Versuchsweswn, Mitteillungen 54, 2.

2. Dobre, A., 1990: Nekateri dejavniki odpiranja gozdnega prostora Raziskovalna naloga, Inštitut za gozdno in lesno gospodarstvo pri Biotehniški fakulteti v Ljubljani, Ljubljana, str. 1- 138.

3. Dietz, P., H. Löffler, \& W. Knigge, 1984: Walderschließung, Eine Lehbruch für Studium und Praxis unter besonderer Berücksichtigung des Waldwegebaus. Verlag Paul Parey, Hamburg und Berlin, p. 1-196.

4. Jeličić, V., 1985: Studija otvaranja odjela 70 i 71 u GJ „Jadovnik - Drvar“ dio, Sarajevo, str. $1-31$.

5. Pentek, T., 2002: Računalni modeli optimizacije mreže šumskih cesta s obzirom na dominantne utjecajne čimbenike, Šumarski fakultet Sveučilišta u Zagrebu, Disertacija, str. $1-271$.

6. Pičman, D., 1993: Utjecaj konfiguracije terena i hidrografskih prilika na ekonomsku opravdanost izgradnje optimalne mreže šumskih prometnica, Šumarski fakultet Sveučilišta u Zagrebu, Disertacija, str. 1 - 112.

7. Pičman, D., \& I Tomaz, 1995: Određivanje težišta odjela primjenom osobnih računala u svrhu izračunavanja srednje udaljenosti privlačenja, Šumarski list 3, Zagreb, str. $91-103$.

8. Sokolović, Dž., 2004: Mogućnost optimalizacije mreže šumskih saobraćajnica u GJ „Plješevica“, Šumarski fakultet Univerziteta u Sarajevu, Magistarski rad, str. $1-125$

\section{Summary}

For the analysis of the forest area accessibility it is necessary to clarify and analyze the term and the volume of the mean skidding distance. Besides the data on total length of forest roads network, mean skidding distance is the distance of different quantities of wood assortment scattered throughout the forest from the particular warehouse.

Calculating mean skidding distance by the computer aid - central point method, is the very fact and accurate way of calculating. Due to the fact that construction of forest roads is very money - consuming with return of investment mainly through lower skidding costs because of decreasing mean skidding distance, it is necessary to choose spatial location of forest roads which maximally influences decreasing mean skidding distance.

In this paper it is represented how it is possible to significantly decrease mean skidding distance with the same length of the forest roads network constructed thanking to proper spatial allocation. Due to this fact the theoretical model of forest roads network has shorter mean skidding distance by 160 meters than existing forest roads network for the nearly same length of forest roads network. 